\title{
Statistical model of wind farms for power flow
}

\author{
Joaquín Mur Jesús Sallán Ángel A. Bayod
}

\begin{abstract}
This paper presents a simplified model to represent a wind farm in a power flow study. This model has been developed taking into account the variability in the generated power from windmills and its normal operation. Its main advantages are its simplicity and the possibility of calculating the voltage in the park's network without having to run a power flow study. Another advantage of the proposed method is that it is based in the fourth-pole theory, widely used in electrical engineering. Finally, the uncertainty of the model is assessed.

Up to now, distributed generation in Spain must inject power with unity power factor. But directive is going to change and some feasible regulations for reactive power are studied, attending specially to voltages across the grid. One possible application of this model is to study the management of reactive power in wind farms. Other possible application is to study the influence of nearby wind farms.
\end{abstract}

Index Terms - wind energy, power flow, reactive power.

\section{INTRODUCTION}

The current legislation for generators included in the special regulation (mainly mini-hydraulic, wind and cogeneration plants up to $50 \mathrm{MW}$ ) in Spain was developed in 1985 (Industry and Energy Ministry order 5/9/85). This order states that the electric plants included in this regulation must operate with unity power factor.

This characteristic was adequate when the percentage of this type of generation was small and the great increase of cogeneration and wind generation was not foreseen.

Moreover, conventional power plans must operate in accordance with procedure 7.4 (distribution network complementary voltage control service, published in BOE $18 / 3 / 2000$ ). However, this procedure is not adapted to the characteristics of the wind farms or the grids to which they are usually connected.

Currently, AENOR is performing a review process of this regulation by means of the workgroup "Grid integration of wind generation", in particular in the group "Wind generators" AEN/CTN 206/SC88. Its goal is achieving a new regulation that allows these power plants to help grid regulation, without causing an excessive increase in cost.

According to the current regulation, reactive power compensation is performed in the plant's point of connection and it does not take into account reactive power consumption and generation in lines and transformers. This worsens the power factor in the border nodes between the distribution and transport networks.

Besides, a power plant modifies the voltage distribution in the grid. Distribution networks are usually limited, not for the maximum thermal current, but for the limits in voltage variation (specially at the end of the line). Because of that, distribution companies prefer distributed generation to be

The autors are with the Electrical Engineering Department of Zaragoza University and CIRCE Foundation, Spain, (Tfn 349767619 20, Fax 34 9767622 26, e-mail: joako@posta.unizar.es). connected to higher voltage levels, where its impact in voltage distribution is very small. However, connecting to a higher voltage level increases the cost of the plant.

Traditionally, the maximum installable generation capability is calculated by using a deterministic load flow, usually based in the worse scenario of minimum load and maximum generation[1]. These studies do not take into account the probability of the different scenarios. However, the standards that establish voltage characteristics are expressed in statistic terms [2].

In addition, wind energy injection modifies the losses in the grid (losses reduction if the zone is mainly consuming and an increase if the area has a generation excess, as it happens in some wind farm concentrations).

The method proposed in this paper can help to evaluate the affection to the net, as well as to compute voltages inside the wind farm.

\section{WIND FARM MODEL}

Within this point it is presented a new method to obtain the equivalent of a wind farm from the characteristics of its components. For the sake of simplicity, the method is applied to a farm composed by a single type of generator with the same load level.

In this model, the farm is divided into the following parts:

- substation (including the park's substation and the portion of the line that goes to the PCC)

- the medium voltage network that connects the substation to the wind turbines.

- the wind turbines (including the MV to LV transformer that usually is located into the tower)

The presented method is general and can be extended to more complex topologies using fourth-pole transformations.

\section{A. FINAL REPRESENTATION OF THE WIND FARM}

\section{a) Farm with fixed tap transformer.}

The equivalent circuit for the farm, that will be obtained at the end of the modeling, will be determined by the park's transmission matrix and the power sent to the grid by a turbine:

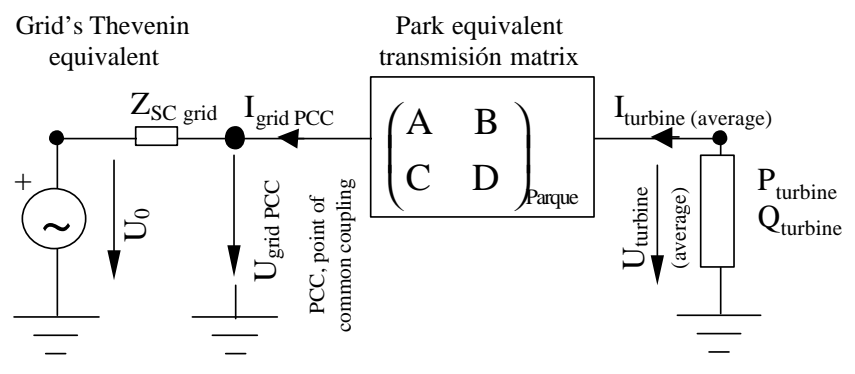

Figure 1: Model of the park with fixed tap transformer using its transmission matrix. 
The basic operations required in order to obtain the transmission matrix for the park are the cascade connection of the elements (equivalent to multiplying the transmission matrixes) and the parallel connection of circuits (equivalent to a weighted sum of the fourth-poles.

Fig. 1 shows the circuit based on the single-phase equivalent. Thus, if the per unit method is not used, power and voltages should be transformed into phase values.

In order to calculate the current injected to the grid, it is necessary to use the transmission matrix considering the turbines as the primary and the network as secondary of the fourth-pole *

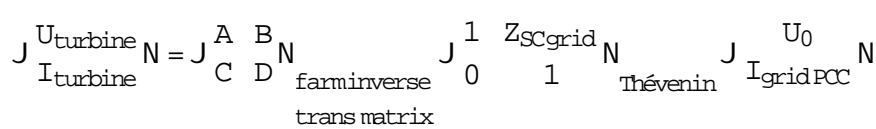

Solving the circuit of fig. 1, two solutions are found. The current injected to the grid, in normal operation and as a function of the transmission parameters and the average power generated by the turbines is:

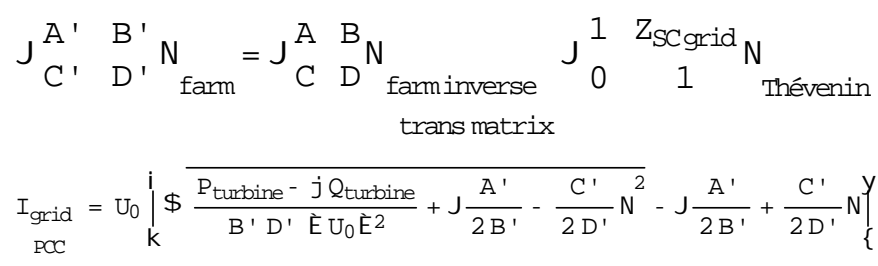

\section{b) Park with tap-changing transformer}

However, if the transformer allows load regulation, it is not operating at the maximum of minimum value and the voltage variation is slow, substation voltage at the MV side of the transformer is almost the commanded value.

According to that, the steady-state simplified model of a park with this type of transformer can be divided into two uncoupled parts. Thus, the grid sees the park as a PQ node. The output of the transformer, seen from the MV circuit side, as a voltage source whose absorbed or generated power corresponds to a PQ node of the grid (power transmitted by a ideal transformer does not depend on the tap).

Park with tap-changing transformer, seen from the grid

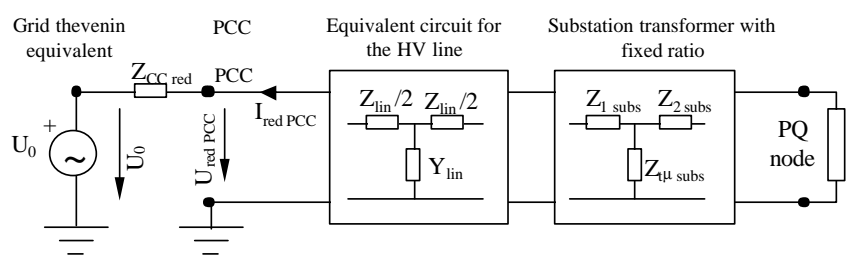

Grid seen from a park with tap-changing transformer

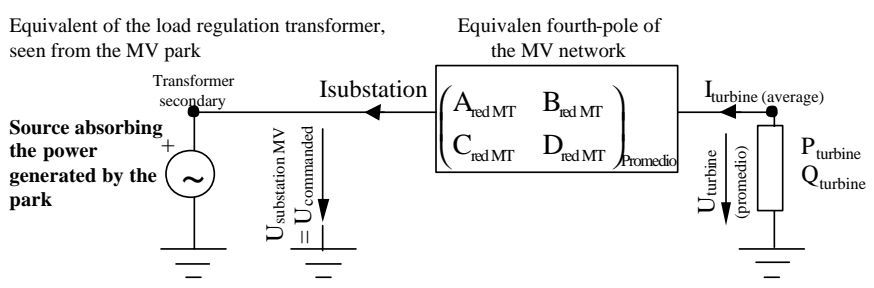

Figure 2: Voltage uncoupled model for parks with load regulation transformer.

\footnotetext{
* The matrix used corresponds to the transmission matrix taking the turbines as primary side and the network as secondary side. Alternatively, the inverse transmission matrix can be used if the network is considered the primary side.
}

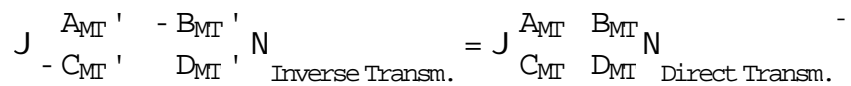

$$
\begin{aligned}
& \mathrm{S}_{\text {farmM }}=-\left|U_{\text {Set Point }}\right|^{2}
\end{aligned}
$$

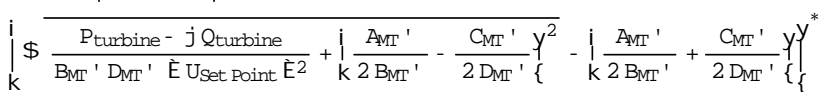

\section{c) Dependence on voltage of the power generated by a turbine}

If the efficiency of a generator can be assessed as a function of voltage and the reactive power compensation policy is known, the turbine can be modeled as a node $S_{\text {turbine }}$ $=\mathrm{P}_{\text {turbine }} \cdot \mathrm{V}^{\mathrm{np}}+\mathrm{j} \mathrm{Q}_{\text {turbine }} \cdot \mathrm{V}^{\mathrm{nq}}$. In this case, in order to calculate $N$ the current fed to the grid, the following equation must be numerically solved:

$$
\begin{aligned}
A^{\prime} U_{0}-B^{\prime} I_{\text {grid PCC }} \text { ä } & P_{\text {turbine Abs@C }} U_{0}-D^{\prime} I_{\text {gridPCC }} E^{\text {nq-1 }}- \\
& -j \text { Qturbine Abs@C } U_{0}-D^{\prime} I_{\text {gridPCC }} D^{\text {nq-1 }}
\end{aligned}
$$

The current obtained not taking into account the voltage dependence can be used as initial value.

\section{B. SUBSTATION MODELLING}

Substation is connected to the grid in the point of common coupling, PCC, with a HV line. In this model, the line and the transformer are going to be represented by their transmission matrixes (single-phase equivalent).

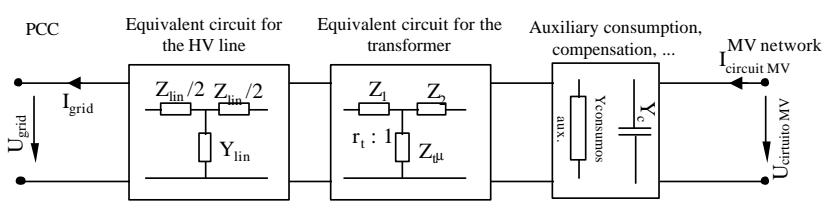

Figure 3: Substation model for the park.

\section{MODELING OF THE UNDERGROUND MV NETWORK}

Turbines are generally connected to an underground MV cable (usually $20 \mathrm{KV}$, although there are also parks with $30 \mathrm{~kW}$ interior network). Usual distances among turbines are around $80-300 \mathrm{~m}$, they have a low consumption or generation of reactive power, and the series impedance of the cable is moderate. Under these conditions, the voltage drop between the first and last turbine is small:

$$
\Delta U \approx \frac{P R+Q X}{U}
$$

The voltage drop between the substation and the closest turbine is also usually small if the substation is located in the park. In some cases, the substation is away from the park because of environmental problems. In these cases the voltage drop in the cable can be a limiting factor when choosing cable and MV network voltage.

\section{C.1 Added model of turbines using the model of moment}

A simple model that provides precise results even with significant voltage drops is based in the voltage drop calculation using the method of moment.

This method is equivalent to concentrating all the generators in its load center of mass, which is at $1 / 2$ of the distance between the first and the last turbine, closest to the 
substation ${ }^{*}$. In the case of parks with different types of cable or different types of generators, this model can be adapted.

Considering that the current injected by the turbines varies in an almost linear way for small voltage variations, like the ones that take place between the first and the last turbine, this model gives very accurate results.

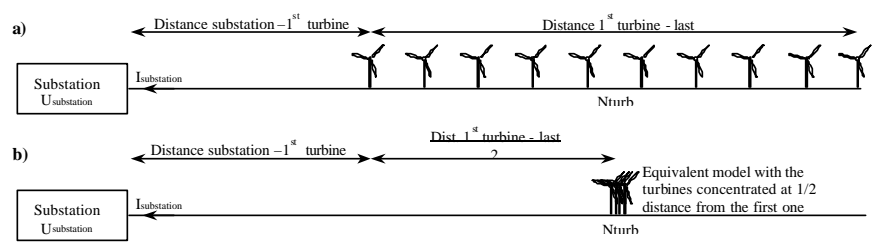

Figure 4: Concentrated model of a MV circuit in a park..

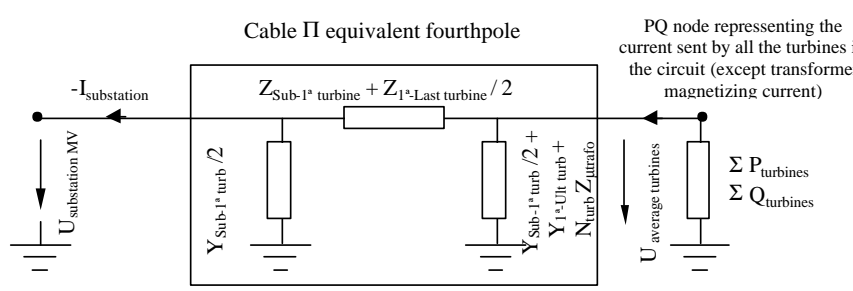

Figure 5: Model of the MV circuit and the turbines of a park.

The power sent to the substation can be found using the parameters of the equivalent fourth-pole of the medium voltage cable.

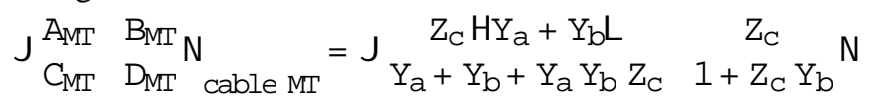
where

$$
\begin{aligned}
& Z_{c}=Z_{\text {Sub-1 } 1^{a} \text { turbine }}+Z_{1^{a} \text {-Ult turbine }} / 2 \\
& Y_{a}=Y_{\text {Sub-1 }} / 1_{\text {turbine }} / 2+Y_{1^{a} \text {-Ult turbine }}+N_{\text {turb }} Z_{\mu \text { trafo }} \\
& Y_{b}=Y_{\text {Sub-1 } 1^{a} \text { turbine }} / 2
\end{aligned}
$$

$\mathrm{N}_{\text {turb }}$ number of turbines in the circuit

$\mathrm{I}_{\text {turbine }}$ average current consumed by the turbines (negative while in production)

$\mathrm{U}_{\text {substation MV }}$ is the cable voltage in the substation terminals $\mathrm{Y}_{1^{\mathrm{a}} \text {-Last turb }}$ is the admittance of the part of the cable between the first and the last turbine

$Y_{\text {Sub-1 } 1^{a}}$ turb is the admittance of the part of the cable between the substation and the first turbine

$\mathrm{Z}_{1^{\mathrm{a}} \text {-Ult turb }}$ is the series impedance of the part of the conductor between the first and the last turbine.

$\mathrm{Z}_{\text {Sub-1 }} \mathrm{1}^{\mathrm{a}}$ turb is the series impedance of the part of the conductor between the substation and the first turbine.

$\mathrm{Z}_{\mu \text { trafo }}$ the magnetizing inductance of the transformer inside the turbine

\section{C.2 Aggregated model of the MV circuit branches}

In order to solve directly, without iteration, a park with various branches on the MV circuit, they must be grouped in a single equivalent branch. The equivalent voltage of the turbines is the weighted average of the circuits and the current send to the substation is the sum of all the circuits.

The voltage in all the branches in the MV circuit is similar if one of the following conditions takes place:

\footnotetext{
* The centre of mass has been calculated using the criterion of equal average voltage in both the equivalent and the original circuits. If the criterion of equal cable power loss had been chosen, the turbines would be placed closer to the substation, at $1 / 3$ of the distance between the first and the last turbine. The voltage criterion is more restrictive than the power one.
}

$\checkmark \quad$ Circuits are short and, thus, the voltage drops are small. $\checkmark \quad$ Circuits are long, but all have similar length and similar number of turbines connected.

Like in the previous part, the equivalent models are based in the linearization of the behavior of the turbines around the average working voltage.

If all the turbines are the same type, it is convenient to include the number of connected turbines in the transmission matrix. By doing this, at the end of all circuits there is the same PQ power corresponding to a single turbine. Inside the matrix, the current is multiplied by the number of turbines in each circuit.

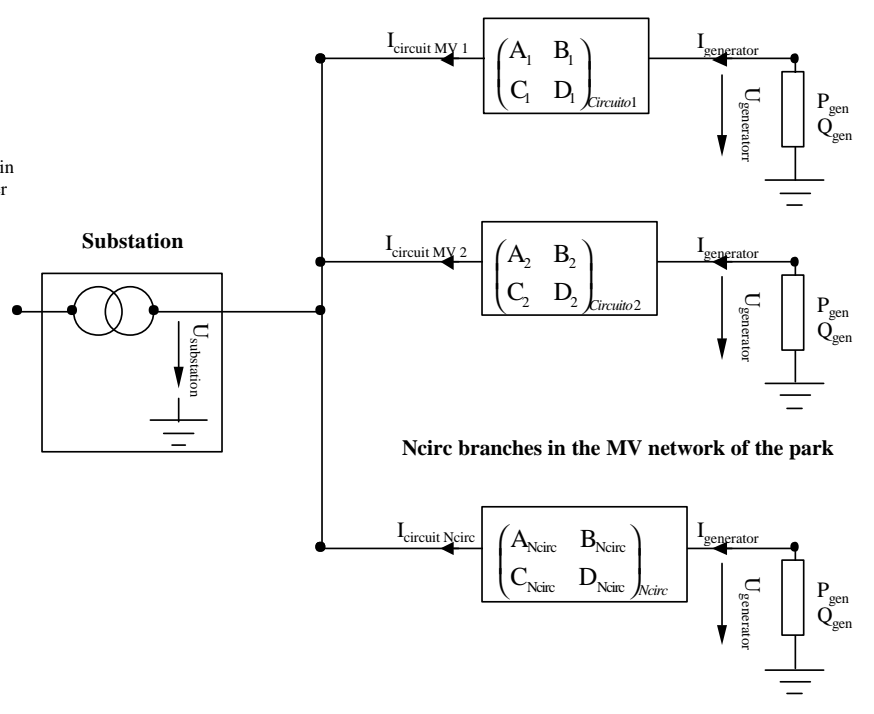

Figure 6: Complete scheme of the medium voltage network, using the aggregated generator model.

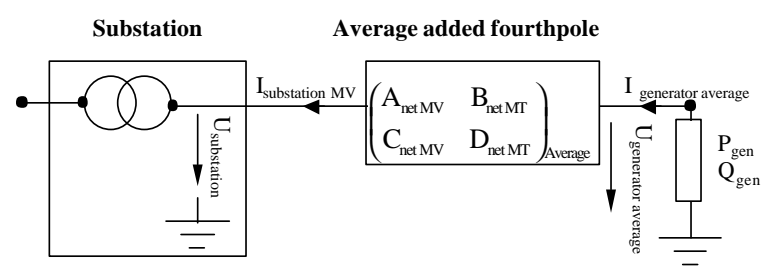

Figure 7: Simplified scheme of the medium voltage network of the park with added generator model.

The parameters of the equivalent fourth-pole are found adding the currents and calculating the equivalent voltage as a weighted average of the voltages in each branch.

$$
\begin{aligned}
& A_{\text {net MV }}=\frac{/{ }_{i=1}^{\text {Ncircuits }} \text { Nturb }_{i} A_{\text {circuit i }}}{/ N_{i=1}^{N c i r c u i t s} \text { Nturb }_{i}} \\
& B_{\text {net MV }}=\frac{/{ }_{i=1}^{\text {Ncircuit }} \text { Nturb }_{i} B_{\text {circuit } i}}{/{ }_{i=1}^{\text {Ncircuits }} \text { Nturb }_{i}} \\
& \mathrm{C}_{\text {net MV }}={ }^{\text {Ncircuits }}, \quad \mathrm{C}_{\text {circuit }} \text { i } \\
& i=1 \\
& \text { Ncircuits } \\
& D_{\text {net MV }}=\quad, \quad D_{\text {circuit }} i
\end{aligned}
$$

This model can be extended to parks with turbines of different types. 


\section{D.MODELING OF THE TURBINES}

\section{D.1 Simplified model of the low voltage circuit}

In the LV side of a turbine, voltage usually is near its rated value thanks to the taps in the transformers. Small voltage changes modify lightly electrical losses and reactive power.

Losses are due to Joule effect $\mathrm{P}_{\mathrm{Cu}} \approx \mathrm{R}_{\mathrm{cc}} \mathrm{S}^{2} / \mathrm{U}^{2}$ and iron losses, $\mathrm{P}_{\mathrm{Fe}} \approx \mathrm{R}_{\mathrm{Fe}} \mathrm{U}^{2}$. Thus, losses depend on voltage with a function of the parameters of the generator. However, the efficiency of the generator is usually high and it does not depend greatly on voltage. Moreover, the effect of voltage fluctuations in electrical losses is small compared to the uncertainty in the power curve of the turbine.

Besides, reactive power consumed by the generator depends on the square of both voltage and current $Q_{\text {gen }} \approx\left(X_{\mu}\right.$ $\left.-X_{\text {cap }}\right) U^{2}+X_{c c} I^{2}=\left(X_{\mu}-X_{c a p}\right) U^{2}+X_{c c} S^{2} / U^{2}$. However, reactive power consumption variations are nearly compensated by the control of the capacitor sets, as long as they are sufficiently sized. In other types of generators, the control acts regulating reactive power.

The stochastic nature of wind affects the control, adding uncertainty regarding which generator (in a machine with two generators or one with different connections) or which capacitor sets are connected. On top of that, some auxiliary consumption shows an intermittent or cyclic behavior.

Because of all these reasons, the turbine can be approximated on a load flow study, in a quite realistic way, by a PQ node whose parameters are a function of the average powers at each wind speed.

It is only necessary to consider the influence of voltage in those studies focused on the behavior of the park in extreme conditions (voltages out of normal operating range, homopolar or inverse sequence voltages,...)

The value of active power as a function of wind speed can be derived from the power curve. The value of reactive power is not usually given by the manufacturer, but it can be measured. In generators with various LV circuits in the transformer, the power in all the LV circuits must be added (A direct measure of power in MV is difficult to perform).

It is desirable to obtain the reactive power curve from the manufacturer as a function of active power or wind speed. If the turbine can control reactive power, it is necessary to know how the command is set (power factor, reactive power, ...) and its limitations (working PQ plane).

\section{D.2 Statistical model of the turbine}

When the turbines do not have the same load level, the previous equivalent circuit has some error. Active and reactive power consumed by the transformers is proportional to the square of the load level in each turbine, not to the square of the average load level. Thus, using that model underestimates the power consumed by the transformers when the load level variation is important.

However, the previous model can be adapted to turbines with different load levels using a statistical approach. The turbine works around an average working point with active and reactive powers $\mu_{\mathrm{Pi}}, \mu_{\mathrm{Qi}}$ and variances $\sigma_{\mathrm{Pi}}{ }^{2}, \sigma_{\mathrm{Qi}}{ }^{2}[3]$. Variance is due both to the difference in power among turbines (spatial variation), and to the time variation of the generated power.

Spatial variation can be estimated from a wind potential study of the site, when measurements are not available. In such a case, this variation can be considered deterministic.
Time variation of power can be estimated from the maximum and minimum power in a time period. Another option is to calculate the variance of the power according to the uncertainty of the power curve. The exact calculation of the joint variance requires knowing the correlation among the time power variations in the turbines. However, in most cases, it can be accepted that the time variations are independent in every turbine.

Looking at the model in figure 7, a fairly simple model of the circuit can be found, based in statistic parameters. The sum of the generated power by the turbines is a statistic variable whose average, for the active and reactive power, is:

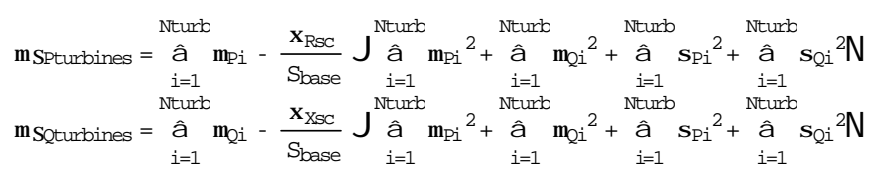

In order to estimate the uncertainty of the power generated by the turbines, it is necessary to have a statistic model of the park. Some dynamic wind models can be found in the literature [4-6]. However, taking into account that the aim of this paper is to find a simple model that can be characterized by few measurements, the following hypothesis are going to be made:

Variance which appears in the previous formulae is due, on one hand to the time variation of the power in a measuring period and on the other hand to the spatial variation (along the circuit) of the power generated by the turbines [7, 8].

Spatial power variation is due mainly to fast fluctuations that can be considered independent form one machine to another. Spatial variations are correlated. For every predominant wind speed there are machines that, in average, generate more than others. This fact is taken into account applying a coefficient $\mathrm{C}_{\mathrm{i}}$, that is equivalent to the efficiency of the location of each turbine, and it is obtained from the micrositting of the park.

In order to consider these effects, the power generated by every turbine is modeled as an average power

$\mathrm{P}=$ average power in a working range

$\mathrm{P}_{\mathrm{i}}=$ power from turbine $\mathrm{i}=\mathrm{C}_{\mathrm{i}}\left(\mathrm{P}+\sigma_{\text {spatial }} \mathrm{X}_{\mathrm{i}}+\sigma_{\text {temporal }} \mathrm{Y}\right)$

$\mathrm{X}, \mathrm{Y}=$ normalized statistical distributions, independent between them

$\mathrm{X}_{\mathrm{i}}=$ distribution that represents the independent fluctuations for every turbine (mainly fast variations due to turbulence, tower shadow...).

$\mathrm{Y}=$ distribution representing the fluctuations that affect proportionally at every turbine (mainly slow power variations)

$\mathrm{C}_{\mathrm{i}}=$ efficiency coefficient of the location of a turbine inside the park, relative to farm average.

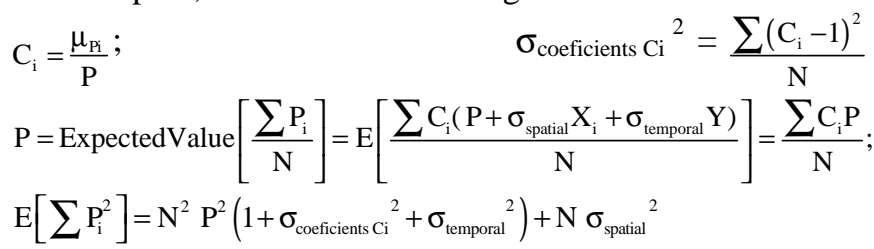

The equivalent average power in the turbine, in low voltage, is the average power of all turbines minus the 
average power consumption in the transformers. Performing the same analysis for the reactive power results in:

$$
\begin{aligned}
\mathrm{P}_{\text {equiv turbine }} & =\mathrm{P}-\frac{\xi_{\mathrm{RCC}}}{\mathrm{S}_{\text {base }}} \sigma_{\mathrm{S} \text { turbine }}{ }^{2} ; \quad \mathrm{Q}_{\text {equiv turbine }}=\mathrm{Q}-\frac{\xi_{\mathrm{XCC}}}{\mathrm{S}_{\text {base }}} \sigma_{\mathrm{S} \text { turbine }}{ }^{2} \\
{\sigma_{\mathrm{S} \text { turbine }}}^{2} & =\mathrm{P}^{2}\left(1+{\sigma_{\text {coeficients Ci }}}^{2}+{\sigma_{\mathrm{P} \text { temporal }}}^{2}+\frac{{\sigma_{\mathrm{P} \text { spatial }}}^{2}}{\mathrm{~N}}\right) \\
& +\mathrm{Q}^{2}\left(1+{\sigma_{\text {coeficients Ci }}}^{2}+{\sigma_{\mathrm{Q} \text { temporal }}}^{2}+\frac{{\sigma_{\mathrm{Q} \text { spatial }}}^{2}}{\mathrm{~N}}\right)
\end{aligned}
$$

It is important to know the variance of $P_{\text {equiv turbina }} \mathrm{y} \mathrm{Q}_{\text {equiv }}$ turbina, because it is going to be the main contribution to the uncertainty on the power generated by the park

$$
\begin{aligned}
& \sigma_{\text {P equiv turbine }}{ }^{2} \approx \mathrm{P}^{2}\left({\sigma_{\mathrm{P} \text { temporal }}}^{2}+\frac{\sigma_{\mathrm{P} \text { spatial }}{ }^{2}}{\mathrm{~N}}\right) \\
& \sigma_{\mathrm{Q} \text { equiv turbine }}{ }^{2} \approx \mathrm{Q}^{2}\left({\sigma_{\mathrm{Q} \text { temporal }}}^{2}+\frac{{\sigma_{\mathrm{Q} \text { spatial }}}^{2}}{\mathrm{~N}}\right)
\end{aligned}
$$

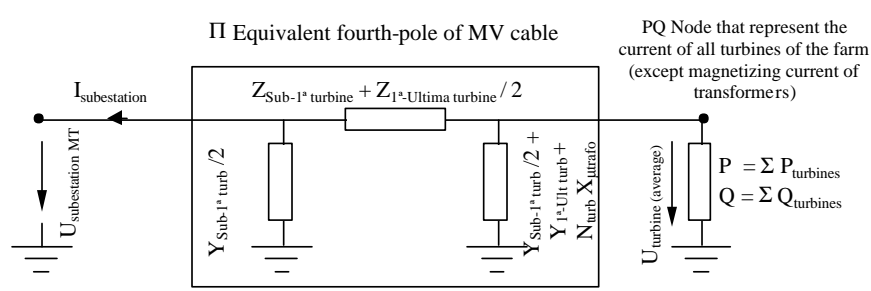

Figure 8: Joint model of the MV circuit and the turbines of a park.

In order to have into account the consumption of active and reactive power when the load level is not the same in all the turbines, it is necessary to decrement the average power

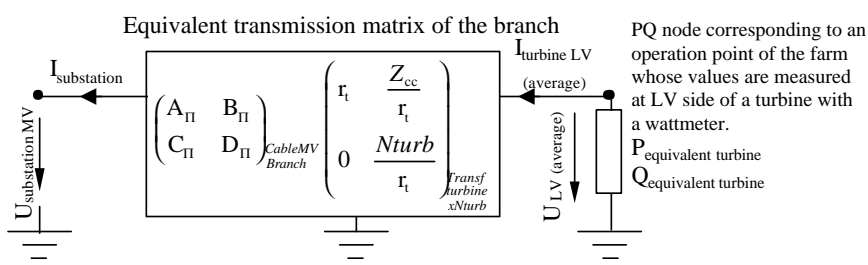

Figure 9: Compact model, compensated for the variability of the power injected by the turbines.

The parameter $\sigma_{\text {coeficients }}$ Ci can be found from the study of the micrositting of the park, or from the correlation of the active and reactive power of each turbine with the average in the park.

The parameter $\sigma_{\text {spatial }}$ can be determined from an operating park, through the remote measurement system, with the correlation matrix. For a farm that is not operating yet, the order can be estimated from, at least two wind measurements and the active and reactive power curves.

The parameter $\sigma_{\text {temporal }}$ can be found measuring the standard deviation of active and reactive power in one turbine whose turbulence is on the same order as the one of the park. It can also be estimated from the maximum and minimum power in the time period, although this method has less precision.

\section{D.3 Electronically controlled generators.}

Models for generators controlled by power converters can be found in the literature. The more frequent configuration is the doubly-fed induction generator, because of the lower cost of the power stages. However, it is becoming more common to find squirrel cage induction generators or synchronous generators connected to the grid through converters, in order to achieve variable speed.

The main problem when trying to model this type of generators is that there is no precise information about the control of the machine. In general, it is useless to try to find a precise model of the machine in a power flow study when the control strategies have to be "guessed" and whose parameters vary in each farm in order to achieve maximum efficiency at every location.

Taking into account that the efficiency of the generator is high, that the voltage is within a narrow range, that usually the information about the control is insufficient and that the power curve has a uncertainty from $3 \%$ to $5 \%$, it is acceptable to approximate the group generator+electronics+auxiliary consumption by a PQ model.

Because of that, unless there is in-deep information about the generator (usually available only for the manufacturer), the model to be used is the simplified one.

D.4 Specific model for the induction generator directly connected to the grid.

The typical induction generator can be modeled as the cascade connection of the fourth-pole corresponding to the equivalent circuit of the generator, power factor correction capacitors and transformer. The variable resistor on the left represents the mechanical power in the generator.

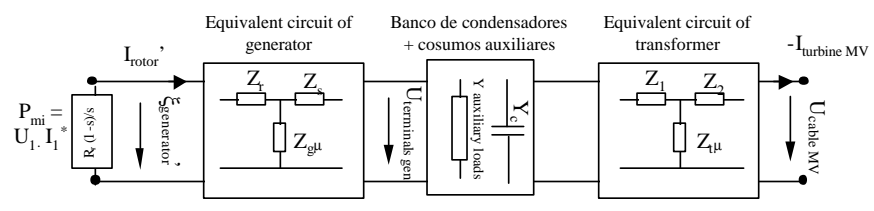

Figure 10: Equivalent circuit of a turbine with a directly connected induction generator.

The transmission matrix is the cascade composition of the transmission matrix of the equivalent circuit of the generator (without the variable resistor), the capacitors and the transformer, ( $\xi_{\text {generator }}$ is the e.m.f.. of the generator in the rotor, referred to the stator).

If it is assumed that all the generators in the circuit work at the same point, the inverse transmission matrix can be found by cascade multiplying all the corresponding fourthpoles.

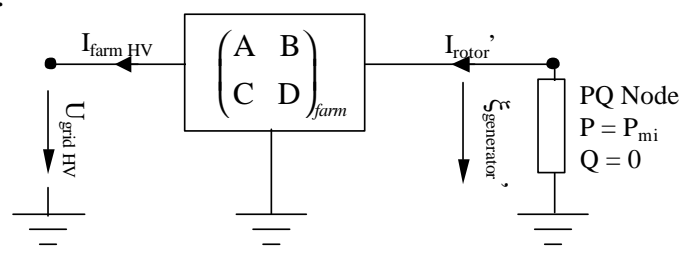

Figure 11: Complete model of a park with directly-connected induction generators, valid when the number of capacitors and the auxiliary consumption can be estimated.

The slip of the generator depends on the terminal voltage. However, induction generators operate with at low slip 
(around 1\% at full load) and it can be considered that blade speed is almost constant and thus, $\mathrm{P}_{\mathrm{mi}}$ does not depend on voltage.

If the number of capacitor banks and the auxiliary consumption can be estimated, the influence of voltage in active and reactive power can be approximated by a power of voltage. In order to obtain the optimum power, the following equation can be solved with the rated values of the turbine.

$$
\begin{aligned}
& \frac{\partial \mathrm{HP}_{\text {turbina@U }} \mathrm{UT}_{\mathrm{MT}} \mathrm{P}_{\mathrm{mi}} \mathrm{DU} \mathrm{UT}_{\mathrm{MT}}{ }^{-\mathrm{n}_{\mathrm{PL}}}}{\partial \mathrm{U}_{\mathrm{MT}}}=0 \quad \hat{\imath} \\
& P_{\text {turbina } @ U_{M T}, P_{m i} D \stackrel{a}{~} P_{\text {turbina }} @ U_{\text {nominal }}, P_{m i} D \diamond}^{i} \frac{U_{M I}}{U_{\text {nominal }}} Y_{\{}^{\mathrm{n}_{P}} \\
& \frac{\partial \mathrm{H}_{\text {turbina }} \mathrm{CU}_{\mathrm{MI}}, \mathrm{P}_{\mathrm{mi}} \mathrm{DU} \mathrm{U}_{\mathrm{MI}}{ }^{-\mathrm{n}_{\mathrm{qL}}}}{\partial \mathrm{U}_{\mathrm{MI}}}=0 \quad \hat{\imath}
\end{aligned}
$$

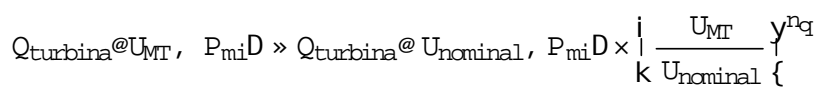

Coefficients $n_{P}$ y $n_{Q}$ can be calculated analytically as a function of two inverse coefficients. For simplicity, the " have been omitted from $A^{\prime}, B^{\prime}, C^{\prime} y D^{\prime}$ ):

$$
\begin{aligned}
& \mathrm{C} 1=\operatorname{Cos} \mathrm{B} \operatorname{ArgB} \$ \frac{\mathrm{HBC}-\mathrm{ADL^{2 } + 4 B D P m i}}{\mathrm{B}^{2} \mathrm{D}^{2}} \mathrm{FF} \\
& C 2=B D H B C+A D L \$ \overline{\frac{H B C-A L^{2}+4 B D P m i}{B^{2} D^{2}}} \\
& \mathrm{n}_{\mathrm{P}}=\mathrm{ReB}-1-\frac{\mathrm{C} 1 \mathrm{HBC}-\mathrm{ADL} \mathrm{L}^{2}-\mathrm{C} 2}{\mathrm{C} 1 \mathrm{HHBC}-\mathrm{ADL} \mathrm{L}^{2}+4 \mathrm{BD} \text { PmiL }-\mathrm{C} 2} \mathrm{~F} \\
& \mathrm{n}_{\mathrm{Q}}=\operatorname{ReB}-1-\frac{\mathrm{HBC}-\mathrm{ADL} L^{2}+8 \mathrm{BD} P \mathrm{Mmi}}{\mathrm{HBC}-\mathrm{ADL} L^{2}+4 \mathrm{BD} P \mathrm{Pmi}} \mathrm{F}
\end{aligned}
$$

For a $600 \mathrm{~kW}$ turbine, the following curves have been obtained.

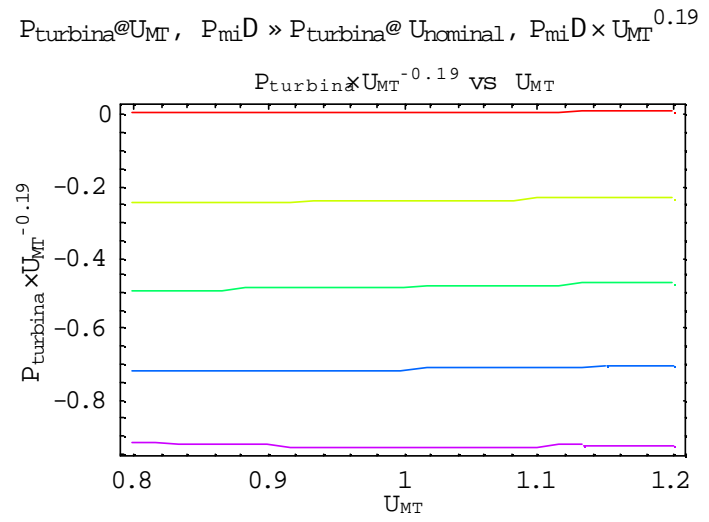

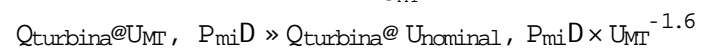

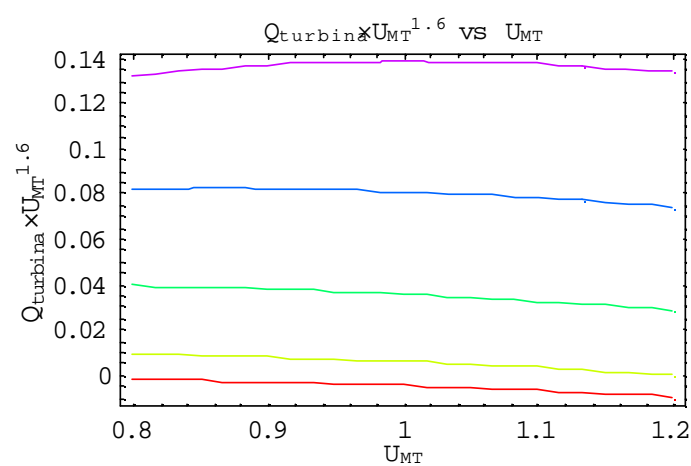

Figure 12: Influence of voltage on active and reactive power.

Powers $n_{P}$ or $n_{Q}$ near cero show little influence of voltage. In the previous example, it can be seen that the influence of voltage in $\mathrm{P}$ and $\mathrm{Q}$ is small because the machine operates with power factor near unity and the resistance in the system is small.

The previous expressions have been obtained with a fixed number of capacitors connected (without power factor regulation with voltage).

The generator emf, referred to the stator, can be calculated from the voltage at the PCC, using fourth-pole theory.

$\mathrm{x}_{\text {generator }}{ }^{\prime}=\mathrm{U}_{\text {grid HV }}$

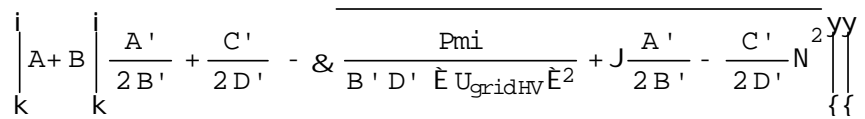

The generator terminal voltage can be easily calculated using the impedances of the generator equivalent circuit.

$$
\underset{\substack{U_{\text {terminal }} \\
\text { generator }}}{ }=x_{\text {generator }}{ }^{\prime} \mid \begin{aligned}
& i \\
& k
\end{aligned}
$$

The minimum voltage at the PCC for stable operation of the generator is:

$$
U_{\text {critical }}=A b s B \frac{2 e \overline{B^{\prime} D^{\prime} P_{m i}}}{B^{\prime} C^{\prime}-A^{\prime} D^{\prime}} F
$$

\section{E. UNCERTAINTY OF THE MODEL}

The uncertainty of the power injected to the grid by the wind farm can be divided in two parts, depending on its origin. One part is due to the stochastic behavior of the wind, and the other is due to the electric model [9].

a) Uncertainty due to the stochastic behavior of the park.

The main source of uncertainty is originated by the variability of the primary source of energy, the wind. This affects directly both $\mathrm{P}_{\text {turbine }}$ and $\mathrm{Q}_{\text {turbine }}$.

In the part dedicated to the stochastic modeling of the turbines, a very simplified model has been used. In practice, wind will interactuate with aerodynamics and the control system. The uncertainties can be found from data measured in a park.

$$
\begin{aligned}
& \mathrm{u}_{\mathrm{P} \text { due to the wind }} \approx \mathrm{P}_{\text {farm }} \sqrt{\sigma_{\mathrm{P}_{\text {temporal }}}^{2}+\frac{\sigma_{\mathrm{P}_{\text {spatial }}{ }^{2}}^{\mathrm{N}}}{\mathrm{u}_{\mathrm{P} \text { due to the wind }}} \approx \mathrm{Q}_{\text {farm }} \sqrt{\sigma_{\mathrm{Q} \text { temporal }}^{2}+\frac{\sigma_{\mathrm{Q} \text { spatial }}^{2}}{\mathrm{~N}}}}
\end{aligned}
$$

Uncertainty due to the stochastic operation can be around $5 \%$, although depends greatly on the measuring period and the power sampling speed. If uncertainty is calculated from field data, these will include the effect of outage of the turbines.

\section{b) Uncertainty due to the simplified model of the park.}

In general, the uncertainties introduced by the park model will be much lower than the ones introduced by the wind, because in normal operation $\Delta \mathrm{V}<3 \%$.

The uncertainty due to the approximate solving of the circuit of the park depends on the voltage difference among turbines. The model is based in the assumption that all the turbines work at the average voltage. In practice, errors are introduced because the behavior is not lineal. The uncertainty associated to the voltage distribution is, as a function of the impedances of the circuit in p.u. 


$$
\begin{aligned}
& \Delta \mathrm{V}_{\text {turb }}=\frac{\mathrm{V}_{\text {max turbine }}-\mathrm{V}_{\text {min turbine }}}{2} ; \\
& \mathrm{S}_{\text {branch } \mathrm{i}} \approx\left(\frac{\mathrm{Z}_{\text {Cable Primera-Ultima turbina }}}{2}+\frac{\mathrm{Z}_{\text {trafo turbine }}}{\mathrm{N}_{\text {turbines }}}\right) \frac{\left|\mathrm{S}_{\text {branch }}\right|^{2}}{\mathrm{~V}^{2}} \\
& \frac{\partial \mathrm{S}_{\text {branch } \mathrm{i}}}{\partial \mathrm{V}_{\text {turb }}} \approx 2\left(\frac{\mathrm{Z}_{\text {Cable First-Last turbina }}}{2}+\frac{\mathrm{Z}_{\text {trafo turbine }}}{\mathrm{N}_{\text {turbines }}}\right) \frac{\left|\mathrm{S}_{\text {circuito }}\right|^{2}}{\mathrm{~V}^{3}} \\
& \mathrm{u}_{\mathrm{P} \text { due to } \Delta \mathrm{V} \text { among turbines }}=\left(\frac{\partial \mathrm{P}}{\partial \mathrm{V}}\right) \frac{\Delta \mathrm{V}}{\sqrt{3}} \approx \\
& \approx \sum_{\mathrm{N} \text { branches }} \frac{2}{\sqrt{3}} \Delta \mathrm{V}_{\text {turb }}\left(\frac{\mathrm{R} \text { Cable First-Last turbine }}{2}+\frac{\mathrm{R}_{\text {trafo turbine }}}{\mathrm{N}_{\text {turbines }}}\right) \mid \frac{\left.\mathrm{S}_{\text {branch }}\right|^{2}}{\mathrm{~V}^{3}} \\
& \quad \approx \sum_{\mathrm{N} \text { branches }} \frac{2}{\sqrt{3}} \Delta \mathrm{V}_{\text {turb to } \Delta \mathrm{V} \text { among turbines }}=\left(\frac{\partial \mathrm{Q}}{\partial \mathrm{V}}\right) \frac{\Delta \mathrm{V}}{\sqrt{3}} \approx
\end{aligned}
$$

There are other sources of uncertainty, like the dependence of generated power with voltage. However, the behavior of the turbine is highly dependent on the technology used and on the parameters of the machine, so it would be necessary to measure or simulate it precisely.

Using these data, the turbine can be represented by a node $S_{\text {turbine }}=P_{\text {turbina }} \cdot V_{\text {p.u. }}{ }^{n p}+j Q_{\text {turbine }} \cdot V_{\text {p.u. }}$. , where the parameters $n_{p} \mathrm{y}_{\mathrm{q}}$ show the influence of voltage. Uncertainty from these parameters is:

$$
\begin{aligned}
& \mathrm{S}_{\text {turbine }}=\mathrm{P}_{\text {turbine }} \cdot\left(\frac{\mathrm{V}_{\text {turbine }}}{\mathrm{V}_{\text {nominal }}}\right)^{\mathrm{np}}+\mathrm{j} \mathrm{Q}_{\text {turbine }} \cdot\left(\frac{\mathrm{V}_{\text {turbine }}}{\mathrm{V}_{\text {nominal }}}\right)^{\mathrm{nq}} \\
& \mathrm{u}_{\mathrm{P} \text { due to } \mathrm{V} \text { different from nominal }} \approx \frac{\mathrm{n}_{\mathrm{p}} \mathrm{P}_{\text {farm }}}{\sqrt{3}}\left(\frac{\mathrm{V}_{\text {turbine }}}{\mathrm{V}_{\text {nominal }}}\right)^{\mathrm{np}-1}\left|1-\frac{\mathrm{V}_{\text {turbine }}}{\mathrm{V}_{\text {nominal }}}\right| \\
& \mathrm{u}_{\mathrm{Q} \text { due to } \mathrm{V} \text { different from nominal }} \approx \frac{\mathrm{n}_{\mathrm{q}} \mathrm{Q}_{\text {farm }}}{\sqrt{3}}\left(\frac{\mathrm{V}_{\text {turbine }}}{\mathrm{V}_{\text {nominal }}}\right)^{\mathrm{nq}-1}\left|1-\frac{\mathrm{V}_{\text {turbine }}}{\mathrm{V}_{\text {nominal }}}\right|
\end{aligned}
$$

\section{c) Uncertainty due to grid voltage}

In the model it has be assumed an infinite bus voltage $U_{0}$ corresponding to the Thevenin equivalent. This voltage varies in parks connected to distribution networks, lines with highly variable consumption... The uncertainty associated to voltage variations in the grid is:

$$
\begin{aligned}
& \Delta \mathrm{V}_{\text {grid }}=\frac{\mathrm{V}_{\text {max grid PCC }}-\mathrm{V}_{\text {min grid PCC }}}{2} \\
& \frac{\partial \mathrm{S}_{\text {farm }}}{\partial \mathrm{V}_{\text {grid }}}=2 \mathrm{I}_{\text {grid PCC }}^{*}+\frac{\mathrm{S}_{\text {farm }}}{\left(\sqrt{\mathrm{B}^{\prime} \mathrm{D}^{\prime} \mathrm{S}_{\text {farm }}^{*}+\frac{\mathrm{V}_{\text {grid }}^{2}}{4}\left(\mathrm{~A}^{\prime} \mathrm{D}^{\prime}-\mathrm{B}^{\prime} \mathrm{C}^{\prime}\right)}\right)^{*}} \\
& \mathrm{u}_{\mathrm{P} \text { due to } \Delta \mathrm{V} \text { in the grid }}=\operatorname{Re}\left(\frac{\partial \mathrm{S}_{\text {farm }}}{\partial \mathrm{V}_{\text {grid }}}\right) \frac{\Delta \mathrm{V}_{\text {grid }}}{\sqrt{3}} \\
& \mathrm{u}_{\mathrm{Q} \text { due to } \Delta \mathrm{V} \text { in the grid }}=\operatorname{Im}\left(\frac{\partial \mathrm{S}_{\text {farm }}}{\partial \mathrm{V}_{\text {grid }}}\right) \frac{\Delta \mathrm{V}_{\text {grid }}}{\sqrt{3}}
\end{aligned}
$$

\section{d) Total uncertainty}

In order to calculate the total uncertainty of the power injected to the utility, due to all the factors previously mentioned, the square addition law must be used. In general, it is normal to use the total extended uncertainty $\mathrm{k}=2$ (interval where power is the $95 \%$ of the time, for a given set of operating conditions).

$$
\begin{gathered}
\mathrm{u}_{\mathrm{P}}=2 \sqrt{\mathrm{u}_{\mathrm{P} \text { wind }}^{2}+\mathrm{u}_{\mathrm{P} \Delta \text { Vgrid }}^{2}+\mathrm{u}_{\mathrm{P} \Delta \text { Vturbines }}^{2}+\mathrm{u}_{\mathrm{P} \text { V } \neq \text { nominal }}^{2}} \\
\mathrm{u}_{\mathrm{Q}}=2 \sqrt{\mathrm{u}_{\mathrm{Q} \text { viento }}^{2}+\mathrm{u}_{\mathrm{Q} \Delta \text { Vgrid }}^{2}+\mathrm{u}_{\mathrm{Q} \Delta \text { Vturbines }}^{2}+\mathrm{u}_{\mathrm{Q} \mathrm{V} \neq \text { nominal }}^{2}} \\
\text { III. CONCLUSIONS }
\end{gathered}
$$

\section{CONCLUSIONS}

The paper shows a statistical model of the farm that can be used in power flow studies, and a methodology for adjusting its parameters to the available data (if it is already operating) or using data from micrositting and power curve of wind turbine (if it is under project state).

The model is fairly simple and reflects the normal operation of the farm. Moreover, the minimum voltage for stable operation is assessed in farms with asynchronous generators.

The uncertainty of the model is also estimated. The sources of uncertainty are stochastic operation of wind farm, employ of a simplified model and grid voltage.

\section{REFERENCES}

[1] Andrés E. Feijóo, José Cidrás "Modeling of Wind Farms in the Load Flow Analysis", IEEE Trans. Power Systems, Vol. 15, No. 2, Feb. 2000, pp. 110-115.

[2] UNE-EN 50160 "Características de la tensión suministrada por las redes generales de distribución".

[3] Andrés E. Feijoo, J. Cidrás, J.L.G. Dórenlas, "Wind speed simulation in wind farms for steady-state security assessment of electrical power systems", IEEE Trans, on Energy Conv., Vol. 14, No 4, Dec. 1999, pp 1582-1588.

[4] Rui M.G. Castro, J.M. Ferreira de Jesus "A Wind Park Reduced-Order Model Using Singular Perturbations Theory", IEEE Trans. Energy Conversion, Vol. 11, No. 4,Dec. 1996, pp. 735-742.

[5] Cristian Nichita et al., "Large Band Simulation of the Wind Speed for Real Time Wind Turbine Simulators", IEEE Trans on Energy Conv., Vol. 17, No. 4, Dec 2002

[6] Sami H. Karaki, Bassel A. Salim and Riad B. Chedid, "Probabilistic Model of a Two-Site Wind Energy Conversion System", IEEE Trans on Energy Conv., Vol. 17, No. 4, Dec 2002

[7] G. McNerney and R. Richardson "The Statistical smoothing of power delivered to utilities by multiple wind turbines", IEEE Trans. on Energy Conv., Vol 7, No 4, December 1992, pp. 644-647

[8] Gary C. Thomann, Michael J. Barfield "The time variation of wind speeds and windfarm power output in Kansas", IEEE Trans. on Energy Conv., Vol. 3, $\mathrm{N}^{\mathrm{o}} 1$, March 1988, PP 44-49.

[9] ISO - Guide to the expression of uncertainty in measurement, 1995. 